\title{
O PRINCÍPIO DA AUTONOMIA DA VONTADE NOS CONTRATOS INTERNACIONAIS - LICC X CONVENÇÃO DO MÉXICO DE 1994 (CIDIP V)
}

\author{
Helena Arriola Sperandio ${ }^{1}$
}

\section{RESUMO}

Com a freqüente prática do Comércio Internacional, e utilização dos contratos internacionais, mister se faz a aplicação do princípio da autonomia da vontade no que tange a escolha da lei aplicável aos contratos. A norma de direito internacional privado do ordenamento jurídico brasileiro - LICC - não acolhe este princípio. No entanto, este já foi acolhido pela LICC de 1.917, não de forma expressa, mas facultava as partes a escolha da lei aplicável aos contratos. A discussão da aplicação deste princípio gira em torno da ordem pública, esta não podendo ser violada sob pena da não validade do princípio no ordenamento jurídico em questão. Da mesma forma, a boa fé é um limite ao princípio da autonomia da vontade. A normativa brasileira, isto é, a Lei de Arbitragem, acolhe em seu bojo o princípio da autonomia da vontade, pois explicita a escolha da lei pelas partes. O princípio da autonomia pode ingressar na ordem jurídica brasileira desde que a Convenção do México de 1994 sobre a lei aplicável aos contratos - CIDIP V - seja ratificada pelo Congresso Nacional. Desta forma, a LICC sofreria alteração, vez que o princípio se encaixaria em seu texto normativo.

\footnotetext{
${ }^{1}$ Advogada, Bacharel em Direito pela Universidade Tuiuti do Paraná em 2003, Pós Graduada em Direito Aplicado pela Escola da Magistratura do Estado do Paraná em 2004, Especialista em Direito Internacional pela PUC - PR em 2005, palestrante no 3 Congresso Brasileiro de Direito Internacional onde publicou o artigo "Contratos Comerciais Internacionais e as Formas de Pagamento no Comércio Internacional" nos anais do respectivo Congresso. Participou no NDI - UFPR de Contratos Internacionais e Arbitragem em 2005, participa do NDI - UFPR em Direito Internacional Público - "Jus Cogens" e do NUPESUL - Núcleo de Estudos de Direito Público do Mercosul.
}

Revista Brasileira de Direito Internacional, Curitiba, v.2, n.2, jul./dez.2005 


\section{ABSTRACT}

With the usual International Commerce practice, and the use of international contracts, the appliance of the principle of autonomy of will is needed when it comes to the choice of the law applicable to international contracts. The private international law rules on the Brazilian Law System (LICC) does not accept this principle. Although, the principle has already been Incorporated by the law of 1917, not in an expressively form, but it was a partie faculty the applicable law in the contracts. The discussion of the application of this principle is centralized in the public order, not being able to be violated under penalty of invalidity of the principle in the Brazilian Law System. In the same way, good will is the limit of the principle of autonomy of will. Brazilian Law, which is, the Arbitration's Law, keep on your normative body the principle of autonomy of will, because allows the law's choice by the parties. The principle of autonomy of will can appear in the Brazilian Law System since the Inter-American Convention on the Law applicable to International Contracts (CIDIP V) - witch happened in Mexico, in 1994 - being approved by the Congress. On these terms, the LICC would sufer changes, for the principle would have been incorporated in by the Brazilian Normative text.

Palavras chave: Contratos Internacionais - Princípio da Autonomia da Vontade - Convenção Interamericana sobre leis aplicáveis aos contratos (CIDIP V)

Keywords: International Contracts - principle of autonomy of will - InterAmerican Convention on the Law applicable to International Contracts (CIDIP $\mathrm{V})$

\section{INTRODUÇÃo}

O presente artigo tem como objetivo o estudo da autonomia da vontade das partes no âmbito obrigacional internacional. 
Anteriormente acolhida pelas regras de direito internacional privado brasileiro, a Lei de Introdução ao Código Civil Brasileiro estabelecia em um de seus artigos a possibilidade das partes, em uma relação obrigacional, escolherem a lei aplicável naquela obrigação.

Já com o advento da Lei de Introdução em 1942, passa a ser vedada a faculdade dos contratantes em escolher a melhor lei aplicável ao caso in concreto, podendo apenas ser aplicada aquela do local de constituição da obrigação.

No entanto, com a realização de algumas convenções internacionais que tratam do tema das matérias de direito internacional privado, e aqui especificamente de contratos internacionais, discutindo a respeito da autonomia da vontade e lei aplicável aos contratos, surgiu a possibilidade da reforma das leis dos Estados para melhor adaptar as normas às necessidades que se verificam no dia-a-dia do Comércio Internacional.

A seguir, explanar-se-á de forma completa as leis vigentes no ordenamento jurídico brasileiro a respeito do assunto e a possível modificação a ser feita com o projeto de Lei $n^{\circ} 4.905 / 95$.

\section{PRINCÍPIO DA AUTONOMIA DA VONTADE COMO ELEMENTO DE CONEXÃO NOS CONTRATOS INTERNACIONAIS}

As discussões acerca da aplicabilidade da autonomia da vontade no campo obrigacional internacional tornam-se cada vez mais freqüentes.

Vários Estados já adotam este princípio, no entanto, o Estado brasileiro ainda não o faz, em virtude das disposições das regras de Direito Internacional Privado.

Assim,

\footnotetext{
"Nos casos onde houver uma escolha de lei, as partes devem procurar identificar claramente quais aspectos do contrato e quais situações devem ser regidas pela legislação preferida. Uma das mais complexas questões a respeito da escolha de lei diz respeito ao efeito dessa escolha em vista da disparidade de normas de direito internacional privado. Pode-se afirmar que simplesmente escolher as regras de um país para reger obrigações poderá não ter a eficácia almejada. Mesmo os sistemas de direito internacional privado que sustentam amplamente o princípio da autonomia da vontade não são absolutos em atribuir força a esta escolha. Todos os sistemas contêm
} 
restrições que invalidam determinadas manifestações de vontade consideradas inaceitáveis. Há sistemas que restringem a possibilidade de escolha, e outros ainda, que proíbem quaisquer opções em matéria de lei aplicável". 2

A autonomia das partes está diretamente ligada a escolha da lei aplicável aos contratos. No Brasil, apenas é possível a escolha do foro onde serão dirimidas as controvérsias, mas não a lei aplicável aos contratos, conforme os ditames do caput do artigo $9^{\circ}$ da Lei de Introdução ao Código Civil.

Este é o parecer de Irineu Strenger, quando menciona que existem algumas restrições por parte de sistemas jurídicos, no que concerne a autonomia contratual, sendo o caso do sistema jurídico brasileiro, analisado sob a ótica formal. ${ }^{3}$

Ainda, Maria Helena Diniz preconiza de forma clara a situação da autonomia da vontade em nosso ordenamento jurídico ao dizer:

"Não há acolhida da autonomia da vontade como elemento de conexão em matéria alusiva a contratos. Os contratantes apenas poderão exercer sua liberdade contratual na seara das normas supletivas da lei aplicável imperativamente determinada pela lex loci contractus. Vigora o princípio da autonomia da vontade em matéria de obrigações contratuais, mesmo na seara internacional, pois poder-se-á considerar como contrato internacional o acordo de vontades em que a conclusão da avença, a capacidade das partes e o objeto contratual estão relacionados a mais de um ordenamento jurídico. Mas será preciso ressaltar que a autonomia da vontade só poderá prevalecer quando não estiver conflitante com norma imperativa ou de ordem pública". ${ }^{4}$

No tocante a autonomia da vontade, Antonio Carlos Rodrigues do Amaral bem assevera que

\footnotetext{
"Através desse novo elemento, dá-se à vontade individual, expressa ou tácita, a faculdade de escolher a lei competente em certas matérias, dentre elas as substâncias e efeitos das obrigações.

Torna-se imperioso esclarecer que se trata da vontade humana agindo própria e autonomamente, elegendo diretamente a lei a ser aplicada em determinado caso concreto, e não a vontade atuando como circunstancia influenciadora do elemento de conexão".
}

\footnotetext{
${ }^{2}$ BASTOS, Celso R., KISS, Eduardo. Contratos Internacionais, p.6.

${ }^{3}$ STRENGER, Irineu. Contratos Internacionais do Comércio, p. 114.

${ }_{5}^{4}$ DINIZ, Maria Helena. Lei de Introdução ao Código Civil Brasileiro Interpretada, p. 277.

5 AMARAL, Antonio Carlos Rodrigues do. Direito do Comércio Internacional-Aspectos Fundamentais. P. 225-226.
} 
A autonomia da vontade, na visão de José Edgard Amorim Pereira, significa que

\begin{abstract}
"as partes, realizando seus contratos no lugar onde normalmente costumam realizá-los, se o fato for anormal, ou no nosso caso, se se tratar de fato comercial internacional, ou ainda, de contrato internacional do comércio, poderão indicar, para apreciá-lo, qualquer direito com que esteja em referência, nacional ou estrangeiro". 6
\end{abstract}

Destarte, a autonomia da vontade

"conduz, por sua vez, a inevitável possibilidade de se deslocar o contrato, tornando-o estranho às normas internas e submetendo-o unicamente ao direito internacional, aos usos e costumes internacionais ou aos princípios gerais do direito".

No entanto, a autonomia da vontade possui certas limitações.

As partes podem, e se assim o ordenamento jurídico que as vige permitir, escolher a lei que aplicarão ao contrato que está sendo celebrado, contudo, com algumas restrições, como por exemplo, as partes não podem escolher um sistema jurídico inexistente, ou não mais vigente, como é o caso do Direito Romano, ou ainda, não pode adotar os pressupostos da lex mercatoria. $^{8}$

Uma questão importante no se refere as limitações da autonomia da vontade é a ordem pública.

No que diz respeito à ordem pública, o artigo $17^{9}$ da Lei de Introdução ao Código Civil é expresso quando menciona que nenhum ato ou declaração de vontade será válido no Brasil se for contrário a ordem pública.

Desta forma, "a escolha da lei que ofenda a soberania, ou a ordem pública ou aos costumes não terá eficácia" ${ }^{10}$

\title{
Para Strenger
}

"A ordem pública sempre desempenha importante papel, devendo-se, porém, distinguir a interna da externa, ou internacional. A primeira noção refere-se aos princípios de base, ou, como muitos chamam, ao Código moral e ético estabelecido e respeitado num sistema jurídico particular. A segunda noção

\footnotetext{
${ }_{7}^{6}$ PEREIRA, José Edgard Amorim. Contratos Internacionais do Comércio, p. 14.

${ }^{7}$ MAGALHẪES, José Carlos de. Contratos Internacionais. P. 72.

${ }^{8}$ STRENGER, Irineu. Op.cit. 114.

${ }^{9}$ Art. 17. As leis, atos e sentenças de outro país, bem como qualquer declaração de vontade, não terão eficácia no Brasil, quando ofenderem a soberania nacional, a ordem pública e os bons costumes.

${ }^{10}$ BASTOS, Celso R., KISS, Eduardo. Op.cit, p.8.
}

Revista Brasileira de Direito Internacional, Curitiba, v.2, n.2, jul./dez.2005 
refere-se a normas legais imperativas, que não podem ser evitadas nem excluídas pelo acordo das partes". ${ }^{11}$

Assim, a não ofensa à ordem pública é um princípio geral em todos os sistemas jurídicos. ${ }^{12}$

Determinadas obrigações, mesmo com a eleição da lei que irá regê-las, não estão subordinadas a autonomia da vontade das partes, visto que possuem um vínculo com determinada lei em virtude das imposições da ordem pública. $^{13}$

Desta forma, "as normas de ordem pública são de incidência imediata e refogem à livre disposição dos contratantes", como bem explicita Georgette Nazo. ${ }^{14}$

Na ótica de Maria Helena Diniz

\begin{abstract}
"A autonomia da vontade no âmbito dos contratos internacionais consiste no exercício da liberdade contratual dentro das limitações fixadas em lei, logo, não há liberdade de escolha pelos contratantes da lei que regerá o contrato. Deveras, o artigo 17 da Lei de Introdução ao Código Civil considera ineficaz quaisquer atos que ofendam a ordem pública interna, a soberania nacional e os bons costumes. O princípio da boa-fé limita a autonomia da vontade nos contratos, inclusive no que atina à aceitação do laudo arbitral". ${ }^{15}$
\end{abstract}

Da mesma forma que Maria Helena Diniz, Georgette Nazo acrescenta que a ofensa ao princípio da boa fé é um limite à autonomia da vontade nos contratos. ${ }^{16}$

Fazendo um paralelo com o sistema da commom law, o princípio da autonomia da vontade também não é absoluto, sendo limitado pela ordem pública e ainda pelas interpretações jurisprudenciais, que instituem precedentes para outros casos, da mesma similitude. ${ }^{17}$

A autonomia da vontade também aparece em nosso ordenamento jurídico na figura da arbitragem.

\footnotetext{
${ }^{11}$ STRENGER, Irineu. Ibidem.

${ }^{12}$ NAZO, Georgette. A Lei Aplicável ao Contrato Internacional e a Ordem Pública. P. 147.

${ }^{13}$ DINIZ, Maria Helena. Op. cit, p. 278.

${ }^{14}$ NAZO, Georgette. Op. Cit, p.147.

${ }^{15}$ DINIZ, Maria Helena. Op. Cit, p. 278.

${ }^{16}$ NAZO, Georgette. Op. Cit, p. 148.

${ }^{17}$ DINIZ, Maria Helena. Op. Cit, p. 278.
} 
A lei o 9.307, de 23 de setembro de 1.996, que instituiu a arbitragem no Brasil, dispõe, logo no Capítulo I, as regras de direito que são aplicadas na arbitragem.

Assim reza o artigo $2^{\circ}$ e seu $\S 1^{\circ}$ da aludida lei:

Art. $2^{\circ} \mathrm{A}$ arbitragem poderá ser de direito ou de equidade, a critério das partes.

$\S 1^{\circ}$ Poderão as partes escolher, livremente, as regras de direito que serão aplicadas na arbitragem, desde que não haja violação aos bons costumes e à ordem pública.

Ao estudar a autonomia da vontade, fazendo um paralelo com a arbitragem, Antonio Carlos Rodrigues do Amaral ensina que é

\footnotetext{
"Interessante notar que no ano de 1996 a posição a favor da autonomia da vontade veio a ser reforçada pela Lei $\mathrm{n}^{\circ}$ 9.307, de 23 de setembro de 1.996, a Lei da Arbitragem. Apesar de pecar pela falta de clareza, há um consenso entre os doutrinadores pátrios de que seu art. $2^{\circ}$ e parágrafos conferem às partes a possibilidade de escolherem "livremente as regras de direito que serão aplicadas na arbitragem", incluindo, sem limitação, os princípios gerais do direito, os usos e costumes e as regras internacionais do comércio. Tal entendimento limita-se porém aos contratos internacionais, já que para os contratos internos, como acima visto, é inclusive vedado cogitar a aplicação de um direito que não seja o brasileiro, aí incluídos os contratos nacionais cujos conflito deverão ser solucionados por arbitragem". ${ }^{18}$
}

Como bem preconiza Luiz Olavo Baptista, o direito que as partes tem de escolher a lei aplicável a um contrato internacional estende-se também a esfera dos tribunais arbitrais. ${ }^{19}$

Destarte, a escolha dos árbitros também é de domínio da autonomia da vontade, devendo a boa-fé reger a arbitragem, inclusive para que seja aceito o laudo arbitral que lhes é vinculativo. ${ }^{20}$

\footnotetext{
${ }^{18}$ AMARAL, Antonio Carlos Rodrigues do. Op. Cit, p. 227.

${ }^{19}$ BAPTISTA, Luiz Olavo. Dos contratos internacionais - uma visão teórica e prática, p. 46.

${ }^{20}$ NAZO, Georgette. Op. Cit, p.148.
} 


\section{REGRAS DE DIREITO INTERNACIONAL PRIVADO NO ORDENAMENTO JURÍDICO BRASILEIRO}

O Direito Internacional Privado Brasileiro é regido pela Lei de Introdução ao Código Civil.

O ordenamento jurídico brasileiro teve em seu bojo duas Leis de Introdução ao Código Civil, a primeira que foi promulgada no ano de 1.917 e revogada em 1.942, e a segunda desta mesma data, que continua em vigor até os dias de hoje, mesmo com a vigência do Novo Código Civil, de 2.002.

Assim, nossa Lei de Introdução permanece inalterada há mais de 60 anos.

Porém, diante da análise da antiga Lei de Introdução, percebe-se que ela era mais benéfica para os agentes do comércio internacional do que a "nova" lei.

A Lei de 1.917 estabelecia em seu artigo 13 a possibilidade da escolha da lei aplicável aos contratos.

Assim,

“o art. 13 da antiga lei ditava que a substância e os efeitos das obrigações seriam determinados pela lei do local onde contraídas, "salvo estipulação em contrário", facultando às partes a escolha da lei competente para dirimir as questões supervenientes". ${ }^{21}$

O elemento de conexão era o local de celebração do contrato (lex loci contractus), contudo, no referido artigo 13, continha a expressão "salvo estipulação em contrário" que dava as partes a liberdade, a autonomia para a escolha da lei aplicável aos contratos, se houvesse outras questões a serem discutidas.

Com a entrada em vigor da Lei de Introdução de 1.942, cessa o poder das partes em escolher a lei que melhor se adaptava as suas obrigações.

$\mathrm{O}$ artigo $9^{\circ}$, que agora substitui o antigo artigo 13을 passa a ter nova redação, por assim dizer:

Art. 9ำ Para qualificar e reger as obrigações, aplicar-se-á a lei do país em que se constituírem.

${ }^{21}$ AMARAL, Antonio Carlos Rodrigues do. Op. Cit, p. 226.

Revista Brasileira de Direito Internacional, Curitiba, v.2, n.2, jul./dez.2005 
Excluiu-se o "salvo disposição em contrário", sendo o elemento de conexão o local da celebração do contrato, sem nenhuma exceção, devendo ser aplicada a lei onde foi constituída a obrigação.

Assim, Maria Helena Diniz bem assevera que

\begin{abstract}
"O art. $9^{\circ}$ da Lei de Introdução é cogente, não podendo as partes alterá-la. [...] Mas, na verdade, será inaceitável a autonomia da vontade para indicar a lei aplicável; haverá tal autonomia para escolha do local para regulamentação de seus interesses ou foro. [...]. Logo, o art. $9^{\circ}$ não excluirá a manifestação da livre vontade dos contratantes se ela for admitida pela lei do local do contrato (lex loci contractus"). ${ }^{22}$
\end{abstract}

Mas, na ótica de alguns autores, como é o caso de Georgette Nazo, esta supressão não significa que não há incidência da autonomia da vontade, vez que

\footnotetext{
"No que tange à atual LICC é necessário bem entender a disposição do art. $9^{\circ}$ e seu respectivo $\S 2^{\circ}{ }^{23}$, pois a expressão "reputa-se" é sinônimo de "presume-se", "entende-se", logo, admite, também, a autonomia da vontade, tal como o Código de Bustamante no art. 185, especificamente para os contratos de adesão.

A circunstancia, pois, de não vir expressa na atual LICC não significa ter sido suprimida ou eliminada [...]. (grifo meu)". ${ }^{24}$
}

Já para Celso Ribeiro Bastos e Eduardo Kiss, se as partes silenciarem sobre a lei de regência das obrigações, será aplicada a lei onde a respectiva obrigação se constituiu. ${ }^{25}$

\title{
4 A CONVENÇÃO DO MÉXICO DE 1.994 SOBRE AS LEIS APLICÁVEIS AOS CONTRATOS - CIDIP V
}

Quando se fala em autonomia da vontade e a possibilidade desta inserir-se no ordenamento jurídico brasileiro, apenas será possível com a ratificação da Convenção sobre Leis aplicáveis aos contratos, realizada no México, no ano de 1.994, sendo a quinta Conferência Interamericana de Direito Internacional Privado, a CIDIP V.

\footnotetext{
22 DINIZ, Maria Helena. Op.cit, p. 278.

${ }^{23} \S 2^{0} \mathrm{~A}$ obrigação resultante do contrato reputa-se constituída no lugar em que residir 0 proponente.

${ }^{24}$ NAZO, Georgette. Op. cit. P. 147.

${ }^{25}$ BASTOS, Celso R., KISS, Eduardo. Op.cit, p.7.
}

Revista Brasileira de Direito Internacional, Curitiba, v.2, n.2, jul./dez.2005 
As CIDIPS, e aqui estudaremos em particular a CIDIP V, são Conferências realizadas pelos Estados que fazem parte da Organização dos Estados Americanos.

Esta conferência trouxe um progresso para vários Estados Americanos, quando disponibilizou em seu corpo normativo a possibilidade das partes escolherem a lei aplicável aos seus contratos.

Assim, ficou estabelecido no Capítulo I, art. 1ํㅜ , que a Convenção determinaria a lei aplicável aos contratos internacionais.

Já no capítulo seguinte, Capítulo II, em seu artigo 7으, restou especificado que o contrato será regido pelas partes.

Assim, é a redação do artigo 70:

Article 7 - The contract shall be governed by the law chosen by the parties. The parties'agreement on this section must be express or, in the event that there is no express agreement, must be evident from the parties' behavior and from the clauses of the contract, considered as a whole. Said selection may relate to the entire contract or to a part of same.

A única problemática aqui encontrada é a ratificação, por parte do Congresso Nacional, desta convenção.

A convenção foi apresentada ao Congresso em 03 de janeiro de 1.994, e o trâmite do Projeto Lei no 4905/95 encontra-se parado desde 08 de fevereiro de 1.997, quando foi pedida a retirada do projeto do Congresso pelo Poder Executivo.

Desta forma, Nádia de Araújo aduz que

"O projeto foi retirado do Congresso Nacional pelo Poder Executivo, e
embora representasse o amadurecimento da posição tomada pelo Brasil no
México, pois não faria sentido ratificar a convenção do México e manter os
princípios da LICC com ela inconsistentes, entendemos que a modificação da
legislação poderia ser feita de outra forma. É preciso enviar a Convenção do
México ao Congresso Nacional e garantir sua aprovação não só entre os
países signatários, mas aproveitar a oportunidade de substituir o artigo $9^{\circ}$ da
LICC pelo seu texto, para que suas disposições sejam aplicáveis a todos os
contratos internacionais conectados com o ordenamento jurídico brasileiro" ${ }^{26}$

${ }^{26}$ ARAÚJO, Nádia. Contratos Internacionais: Autonomia da Vontade, Mercosul e Convenções Internacionais, p. 199.

Revista Brasileira de Direito Internacional, Curitiba, v.2, n.2, jul./dez.2005 
Assim, só será possível a alteração das regras de direito internacional privado brasileiro com a ratificação da Convenção do México de 1994, que estava estagnada no Congresso até o ano de 1.997 e fora retirada do mesmo há quase 10 anos.

Desta forma, o artigo 9ำ da Lei de Introdução permanece inalterado, não sendo possível às partes escolherem a lei que pretendem aplicar ao contrato, embora o Brasil já tenha concordado com o advento do princípio da autonomia das partes, na Convenção de 1.994.

Pode-se dizer que este é um retrocesso no campo normativo, pois, seria muito mais benéfico tanto para as partes como para as relações comerciais internacionais se os contratantes pudessem escolher a lei que aplicariam ao instrumento contratual.

No entanto,

“A realização da Conferência do México representou um grande avanço para o tema dos contratos internacionais no continente. Com efeito, até a elaboração da Convenção sobre o Direito Aplicável aos Contratos Internacionais, a maioria dos países não contemplava, ao menos de forma expressa, a autonomia da vontade em sua legislação interna. Nesse ponto, a convenção representará um grande avanço para os países a ratificarem". ${ }^{27}$

\section{CONSIDERAÇÕES FINAIS}

Diante do trabalho realizado, pôde-se estudar a fundo a autonomia da vontade em nosso ordenamento jurídico, sabendo quais são os seus propósitos, as suas limitações e suas abrangências.

No entanto, percebe-se que a autonomia da vontade pode levar um certo tempo para entrar em vigência em nosso País, pois, como foi estudado anteriormente, o Projeto de Lei que ratificaria a Convenção do México de 1.994 atinente aos Contratos Internacionais foi retirado do Congresso.

Isso com certeza passa a ser um atraso em nossa legislação, pois vários Estados já estão adotando o Princípio da Autonomia da Vontade, o que torna o cotidiano das relações comerciais internacionais mais fáceis, bem como apresenta benefícios as partes contratantes.

\footnotetext{
${ }^{27}$ ARAÚJO, Nádia. Op. Cit, p. 202.
}

Revista Brasileira de Direito Internacional, Curitiba, v.2, n.2, jul./dez.2005 
Ademais, pôde-se perceber também que a Lei de Introdução de 1.917 era mais "moderna" do que a atual lei, pois concebia em seu texto o princípio da autonomia da vontade, a faculdade da escolha das leis pelas partes contratantes.

\section{REFERÊNCIAS}

AMARAL, Antônio Carlos Rodrigues do. (Coord.). Direito do Comércio Internacional - Aspectos Fundamentais. São Paulo: Aduaneiras, 2004.

ARAÚJO, Nádia de. Contratos Internacionais: Autonomia da Vontade, Mercosul e Convenções Internacionais. 3를 Edição. Rio de Janeiro: Renovar, 2004.

BAPTISTA, Luiz Olavo. Dos Contratos Internacionais - Uma visão teórica e prática. São Paulo: Saraiva, 1994.

BASTOS, Celso Ribeiro; KISS, Eduardo Amaral Gurgel. Contratos Internacionais. São Paulo: Saraiva, 1990.

DINIZ, Maria Helena. Lei de Introdução ao Código Civil Brasileiro Interpretada. 9a Edição. São Paulo: Saraiva, 2002.

GARCEZ, José Maria Rossani. Contratos Internacionais Comerciais Planejamento, Negociação, Solução de Conflitos, Cláusulas Especiais, Convenções Internacionais. São Paulo: Saraiva, 1994.

MAGALHÃES, José Carlos de. Contratos Internacionais. Revista Forense. Rio de Janeiro, vol. 294, p. 71-80.

NAZO, Georgette. A Lei Aplicável ao Contrato Internacional e a ordem Pública. Revista de Direito Civil - Imobiliário, Agrário e Empresarial. P. 143-154, Ano 10, Jan-Mar 1986.

PEREIRA, José Edgard Amorin. Contrato Internacional do Comércio. Revista de Direito Mercantil - Industrial, Econômico e Financeiro, $n^{\circ} 74$, p. 11-22, AbrilJunho 1989.

RODAS, João Grandino. Contratos Internacionais. 2ª Edição. São Paulo: Editora Revista dos Tribunais, 1995.

STRENGER, Irineu. Contratos Internacionais do Comércio. $3^{\text {a }}$ Edição. São Paulo: LTR, 1998. 